\title{
Erythropoietin and Diabetic Retinopathy
}

Francesco Semeraro $^{1}$, Anna Cancarini ${ }^{1 *}$, Eliana Forbice ${ }^{1}$, Francesco Morescalchi ${ }^{1}$, Simone Donati ${ }^{2}$, Claudio Azzolini ${ }^{2}$ and Ciro Costagliola $^{3}$

${ }^{1}$ Department of Medical Surgical Specialties, Radiological Sciences and Public Health, University of Brescia, Italy

${ }^{3}$ Department of Surgical and Morphological Sciences, Ophthalmology Section, University of Insubria, School of Medicine, Italy

${ }^{4}$ Department of Medicine and Health Sciences, University of Molise, Campobasso, Italy

\begin{abstract}
Diabetic retinopathy (DR) is the main cause of visual impairment in industrialized countries. Great efforts are in place to search for new therapies able to prevent the development of DR and the onset of its complications. At present, therapy consists of anti-VEGF intra vitreal injections and is aimed at preventing the main causes of visual impairment, that is, macular oedema and retinal proliferation. However, the current knowledge has led us to hypothesize about the roles of other factors implicated in the pathogenesis of macular oedema and retinal proliferation; erythropoietin (EPO) is one such compound.
\end{abstract}

The aim of the work was to review the recent literature on the applications of EPO within the context of DR etiopathogenicity.

Keywords: Erythropoietin; Diabetic retinopathy; Retina angiogenesis; Neuroprotection

\section{Abbreviations: DR: Diabetic Retinopathy; EPO: Erythropoietin \\ Introduction}

Erythropoietin (EPO) is a cytokine that was purified for the first time in 1977; its applications in clinical practice began in 1988 when recombinant human erythropoietin (rhEPO) was registered, primarily for the treatment of anaemia in chronic kidney disease (CKD). Since then, the applications of rhEPO have grown, and now it is used to treat not only renal anaemia but also anaemia resulting from prematurity and malignancy/chemotherapy/radiotherapy-related anaemia, myelodysplasia, HIV, and neuroprotection [1].

In ophthalmology, interest in this molecule has grown only recently, thanks to the discovery of its involvement in the etiopathogenesis of proliferative retinopathies [2] and neuroprotection [3]. Moreover, retinal production of EPO and the retinal presence of its receptor (EpoR) have been discovered in recent years [4].

The aim of this review is to elucidate the current knowledge on the role of EPO in the etiopathogenesis of diabetic retinopathy (DR) and any possible roles of EPO in a therapy for this dangerous and formidable complication on the basis of data available in the current literature.

\section{Diabetic Retinopathy}

$\mathrm{DR}$ is a very frequent microvascular complication of diabetes mellitus (DM); in fact, it is the leading cause of legal blindness in industrialized countries $[5,6]$.

DR has several pathogenetic steps: initially, glycosylation of structural proteins leads to the loss of pericytes of the retinal vessels; the consequences include bulging (micro-aneurysms) and rupture (micro-haemorrhages) of capillaries, which are associated with the extravasation of fluids and consequent retinal oedema. The consequence of these vascular abnormalities is retinal ischemia, which in turn, releases proangiogenic factors leading to many abnormal new vessels that proliferate and coat the cortical vitreous surface (proliferating DR). During this step, there is a higher risk of massive haemorrhage (vitreous haemorrhage) and tractional retinal detachment; when this damage occurs, the chances of recovering vision are poor. This is the reason why many efforts have been made to both inhibit the growth and block the development of DR; many of these studies have focused on retinal neoangiogenetic factors in order to prevent one of the first steps of DR.

The most important cytokines and growth factors involved in neoangiogenesis have been well known for a long time; they are vascular endothelial growth factor (VEGF), interleukin 6 (IL-6), insulin-like growth factor (IGF), and the products of non-enzymatic glycosylation [7].

However, suppression of these factors does not completely inhibit ischemia-induced angiogenesis, suggesting the possible involvement of other angiogenic factors. Recently, it has been shown that EPO also has angiogenic activity similar to that of VEGF: in vitro, it stimulates proliferation, migration, and angiogenesis in endothelial cells that express EpoR. Furthermore, inhibition of EPO by soluble receptors for EPO (sEpoR) blocks angiogenesis in vivo.

Over the past years, many studies have suggested that EPO also has a neuroprotective role, which could play a protective role in the retina. For these reasons, in regard to DR, EPO could be considered a "twofaced Janus": it is a pathogenetic factor, but it also plays a protective role in proliferative diabetic retinopathy (PDR).

\section{Erythropoietin}

$\mathrm{EPO}$ is a $30.4-\mathrm{kDa}$ glycoprotein hormone, formed by a single polypeptide chain of 165 amino acids [8], whose gene is located

*Corresponding author: Anna Cancarini, Department of Medical Surgical Specialties, Radiological Sciences and Public Health, University of Brescia, Brescia, Italy, Postal address: P.leSpedaliCivili 1, 25123 Brescia, Italy, Tel: +39 030 3995308; Fax: +39 030 3995028; E-mail: acancarini@gmail.com

Received July 25, 2013; Accepted August 17, 2013; Published August 23, 2013 Citation: Semeraro F, Cancarini A, Forbice E, Morescalchi F, Donati S, et al. (2013) Erythropoietin and Diabetic Retinopathy. J Diabetes Metab 4: 283 doi:10.4172/2155-6156.1000283

Copyright: (C) 2013 Semeraro F, et al. This is an open-access article distributed under the terms of the Creative Commons Attribution License, which permits unrestricted use, distribution, and reproduction in any medium, provided the original author and source are credited. 
on chromosome 7 (7pter-q22) [9]. The conformation of EPO is 4 antiparallel alpha-helices connected by 2 loops, 1 long and 1 short; it is very similar to other hormones such as growth hormone-releasing hormone $(\mathrm{GRH})$, prolactin (PRL), IL-6, and granulocyte colonystimulating factor (G-CSF) [10]

The major site of EPO production during foetal development is the liver, while in adults, the main site of production is the kidney $[11,12]$. Recently, production of EPO has been found also in many other tissues, including the female genital tract, placenta, testes, brain, and human retina [13-15].

The main stimulus for the production of EPO is hypoxia, which causes an increase in the expression of hypoxia-inducible factor (HIF) [16]. HIF increases the transcription of genes producing molecules involved in mechanisms of adaptation to low levels of oxygen, such as EPO, VEGF, glucose transporters, and glycolytic enzymes [17]. It had been hypothesized that both the isoforms of HIH-HIF-1 and HIF-2may affect expression of the EPO gene; however, it has been suggested recently that HIF-2 is the main factor that stimulates expression of the EPO gene in hypoxic conditions [18]. In contrast, IL-1 and tumour necrosis factor alpha (TNFa) inhibits the production of EPO in vitro [19].

EPO acts by binding to a trans-membrane receptor (EpoR) that belongs to the superfamily of type I cytokine receptors and is predominantly expressed on hematopoietic progenitor cells. Recently, EpoR has also been identified in non-hematopoietic cells, such as in endothelial cells, cardiac myocytes, neurons, liver cells, retinal cells, the gastrointestinal tract, and the reproductive system [20-23]. In some organs (eyes, brain, spleen), EpoR expression is increased during hypoxia [24].

EPO was initially described as a molecule playing a sole role as a primary regulator of erythropoiesis; it stimulates the production, survival, and differentiation of erythroid progenitor cells, mainly on colony-forming-unit-erythroid (CFU-E), and inhibits apoptosis [25].

The presence and production of EPO and EpoR in nonhematopoietic tissues leads one to consider EPO to be a pleiotropic cytokine that mediates many biological activities beyond haematopoiesis. At present, it is believed that EPO is a growth factor with anti-apoptotic, anti-oxidant, anti-inflammatory, and proangiogenic functions [14]. Recent evidence supports EPO acting as a paracrine growth factor.

EPO has angiogenic activity in vitro and stimulates endothelial cells to proliferate and migrate [26]; administration of EPO has a protective effect on endothelial cells [27]. The effectiveness of EPO in stimulating angiogenesis in vivo and in vitro reaches the same degree as VEGF $[28,29]$.

EPO also promotes the survival of endothelial and neuronal cells $[30,31]$. Recently, it is also known that EPO is a potent anti-apoptotic factor for cells presenting EpoR, especially nerve cells [14].

In the recent years, many experimental studies have shown that EPO has a significant neuroprotective effect both in cell cultures and in animal models of nervous system diseases [20-22]. EPO is a potent promoter of neuronal survival and can prevent damage to the nervous system resulting from conditions of reduced oxygen tension, metabolic stress, or neurotoxic agents [3,32]. EPO prevented apoptosis and protected neuronal cells from damage in experimental models of ischemic and hypoxic injury to the central nervous system [33]. In cerebral ischemia, a rapid up-regulation of EpoR occurs, followed by an increase in localised production of EPO [34]. In both the brain and kidney, EPO production is regulated by an ischemia-dependent mechanism. These data are derived from models of traumatic brain injury [35], damage to the spinal cord [36], Parkinson's disease, oxidative stress [37], and chemical neurotoxicity [38].

Exogenous administration of EPO in rodents saves hippocampal neurons from lethal ischemic damage [35,39], and provides neuroprotection after traumatic brain [35] or spinal cord injuries [36]

\section{Erythropoietin and Eye}

It has been shown that EPO is produced locally in the retina [13]; also, its receptor (EpoR) is expressed in the human retina [4]. The exact sites of EPO and EpoR expression in the retina have not yet been defined with certainty. In one study, it was shown that EPO is expressed in amacrine and bipolar cells, and EpoR is expressed in the ganglion cells, amacrine cells, and astrocytes of the mammalian retina [40]. Another study showed expression of the EPO gene and its receptor in different layers of the neurosensory retina and retinal pigment epithelium [4].

Still, in a murine model of oxygen-induced retinopathy, the EPO protein was localized mainly at the level of the internal segment of the photoreceptors [41], and in an autoptic study of diabetic patients without diabetic retinopathy, the EPO receptor has been identified in the neuroretina and retinal pigment epithelium [4]. Another study showed the presence of the EPO receptor in the epiretinal membrane in eyes affected by proliferative diabetic retinopathy [42]. Chen et al. showed that the receptor for EPO should be expressed in each layer of the inner retina, and especially in the ganglion cell layer [41]. Additionally, Killic et al. demonstrated the expression of the receptor at the level of the ganglion cells [24]; while Grimm et al. [43,44] demonstrated evidence of its localization at the level of the photoreceptor layer [43].

If the location of EpoR in the retina is not yet completely defined, it is certain that the expression of the receptor in the retina is strongly influenced by the presence of hypoxia. Hypoxia is indeed a powerful stimulus for the expression of EPO and its receptor, and a growing amount of evidence suggests that hypoxia may induce changes in the expression of EPO receptors in the eye. It seems that hypoxia (through HIF-1) results in an up-regulation of both EPO in the retina and the expression of receptor for EPO [43]. Animal studies show that levels of the receptor are greater in retinas exposed to ischemic conditions than in normal retinas [44].

Another study that investigated the distribution of the EPO receptor in the retina revealed differences between the central and peripheral retina. EpoR is expressed in the ganglion cell layer at the posterior pole of human eyes in non-diabetic subjects, while it is not expressed at the level of the inner and outer nuclear layers or at the level of the plexiform layer. In contrast, in the diabetic retina at the posterior pole there is greater expression at the photoreceptor level than in the ganglion cell layer. The increased expression in the photoreceptor level is very probably linked to an earlier state of hypoxia and the great ischemic susceptibility of these cells [45].

In the peripheral retina, the thickness and the numbers of cells normally decrease. In non-diabetic eyes, there is a progressive and corresponding reduction in the concentration of EpoR. In contrast, in the diabetic retina, there is also a significant increase in EpoR in the periphery; in this case, the increased expression of EPO receptors is also linked to the ischemia/hypoxia that affects this peripheral area [45]. In ischemic conditions, like those that occur in diabetic retinopathy, there may be an up-regulation of the expression of EpoR in the photoreceptor 
layer and in the peripheral retina. The increase in EPO receptors may reflect an increase in hypoxia, and this could be a system by which the body tries to protect the retina from hypoxia-induced damage.

EPO also appears to have a potent neuroprotective effect $[25,33,46-$ 48], in particular, against neurological damage from ischemia and reperfusion and light-induced retinal degeneration in animal models $[35,40,49,50]$. There is increasing evidence that EPO is a eurotrophic factor not only in the brain, but also in the retina [46]. EPO can protect retinal ganglion cells from degeneration induced by reperfusion after ischemia $[40,51]$ and promotes the survival of ganglion cells, as demonstrated in a mouse model of glaucoma [52].

EPO is able to restore proteins at the tight junction level and protect the blood-brain barrier through increased permeability induced by VEGF [53]. Because of the resemblance between the bloodbrain and blood-retinal barriers, is possible that EPO also acts as an anti-permeability factor in the retina [52]. In fact, when administered systemically as a treatment for anaemia in diabetic patients with renal impairment [54], improvements were noted in the patients' diabetic macular oedema.

EPO also has an anti-inflammatory effect on the brain [55], and this action could be effective on the retina [2].

The expression of EPO and its receptor in the retina are noticeable in cases of apoptosis caused by oxidative stress, such as that induced by light [56]. Furthermore, it has been shown that EPO can reduce apoptosis associated with oxidative damage in retinal pigment epithelial cells in culture [57]. Apoptotic cell death is implicated in many degenerative retinal diseases, including retinitis pigmentosa, glaucoma, and macular degeneration [46]. In oxidative stress, up-regulation of EPO provides neuroprotection against retinal degeneration. Studies on mice have shown that an increase in EPO can protect the retina from damage induced by light after the retina has been exposed to a hypoxic environment [43].

In conclusion, EPO is a powerful physiological stimulus for the mobilization of endothelial progenitor cells [58]; therefore, EPO could have a significant role in the turnover of endothelial progenitor cells in damaged areas of the retina [2].

\section{Erythropoietin and Diabetic Retinopathy}

Diabetic retinopathy (DR) is the leading cause of blindness in working-age patients in industrialized countries $[5,6]$.

Macular oedema is the leading cause of visual impairment in patients with type 2 diabetes mellitus [59] and is caused by fluid accumulation compromising the internal blood-retinal barrier $[59,60]$. VEGF (vascular endothelial growth factor) and other proinflammatory cytokines seem to be the main factors involved in the pathogenesis of diabetic macular oedema [61,62]. However, knowledge about the modulators of the permeability of the blood-retinal barrier in macular oedema is limited.

Recent studies have shown that, although VEGF is the main mediator of retinal angiogenesis, its inhibitional one is not enough to prevent retinal neovascularisation in eyes receiving this treatment [63]. Therefore, it was hypothesized that there must be other important ischemia-induced angiogenic factors, one of which may be EPO.

Similar to VEGF, EPO plays an important role in retina angiogenesis [44]; recent studies have demonstrated intraretinal production of this molecule, which has an angiogenic potential equal to that of VEGF
$[28,64]$. The inhibition of the expression of EPO in mRNA (small interfering RNA) is effective in suppressing retinal neovascularisation [41]. Therefore, EPO could be an important factor involved in stimulating angiogenesis in proliferative diabetic retinopathy.

Intraocular levels of EPO are increased in diabetic retinopathy $[4,13,64]$. The cause of high levels of EPO in the vitreous humour of patients with diabetic macular oedema and proliferative DR remains unclear $[13,64,65]$.

The increase in vitreous EPO and in the proliferation of DR could in part depend on increased serum diffusion resulting from the high permeability of retinal vessels; however, this seems to be mainly caused by increased local production; the blood concentration is lower than that in the vitreous humour [66].

Increased levels of EPO gene expression were found in human and animal retinas $[13,64]$, and EpoR immunoreactivity was detected in epiretinal membranes in diabetic eyes [42]. Increased expression of EPO was found both in the retinal pigment epithelium and in the neuroretina of diabetic eyes $[4,13]$. The mRNA expression of EPO is increased, especially in the pigment retinal epithelium, compared to the neurosensory retina [4].

The retina is one of the most metabolically active tissues of the human body and therefore is very sensitive to reductions in oxygen tension. Hypoxia is the major stimulus of both systemic and intraocular production of EPO; in fact, elevated levels of intravitreal EPO are associated with ischemic ocular diseases such as proliferative diabetic retinopathy and occlusion of the central retinal vein $[13,64,67]$.

High intravitreal levels of EPO were found both in the presence of proliferative diabetic retinopathy and in diabetic macular oedema without ischemia $[13,64,65]$. This suggests that the increase in vitreous EPO not only results from ischemia, but also from other factors [13]. The mechanism that induces increased production of EPO in the retinas of diabetic patients is still not completely understood, even if the main stimulus is hypoxia, which increases the gene transcription of the gene for EPO through HIF-1.

Watanabe et al. [65] observed an increase in EPO levels in the vitreous humour of patients with inflammatory eye diseases $[28,64]$, and since inflammation plays a pathogenic role in DR [68], this may contribute to the high levels of EPO observed in diabetic patients. Hyperglycaemia may be another factor that induces production of EPO. Although there are no studies evaluating the effect of glucose on the retinal expression of EPO, a direct relationship has been demonstrated in a hamster ovary cell line [69].

Moreover, the reduction of EPO catabolism may contribute to the high levels of EPO detected in the retina and in the vitreous humour of diabetic donors. The glycosylation of EPO reduces its affinity for EpoR [70]. Given that EPO is degraded only in cells expressing EpoR, and that the link determines the degree of intracellular degradation [71], it is possible that a high level of glycosylation of EPO is associated with reduced clearance of EPO.

The consequences of EPO expression in diabetic retinopathy remain to be elucidated, but to date, the available knowledge suggests that it has a protective role, at least in the early stages of diabetic retinopathy.

Retinal neurodegeneration is an early event in diabetic retinopathy, and therefore, it is possible that a high production of EPO is necessary for it to act as a neuroprotective factor. Indeed, there are numerous 
experimental studies that demonstrate the beneficial role of EPO in cases of neurological insults such as hypoxia, ischemia [40], photooxidation [43], and increased intraocular pressure [52]. Layton et al. $[72,73]$ showed that in culture, the retinal neurotrophic effect of EPO is attenuated by high concentrations of glucose, similar to those present in diabetes. Recently, it was shown that in early diabetes, the exogenous administration of EPO through intravitreal [73] or intraperitoneal injections [74] protects the nervous and vascular structures in murine models. There is increasing evidence that demonstrates the neuroprotective ability of EPO both in the brain and in the retina $[33,46]$.

EPO protects retinal pigment epithelial cells through increased permeability; this is mainly mediated by JAK2 and PI3/AKT signalling pathways. Furthermore, treatment with EPO leads to an increase in intracellular free $\mathrm{Ca}^{2+}$ into retinal pigment epithelial cells, stimulating the flow from the extracellular space. This could contribute to the protective effect of EPO to barrier functions. By using an in vitro bovine blood-brain barrier model, it has been demonstrated that EPO protects against increased permeability induced by VEGF and protects the tight junction [53]; similar results were found in a murine model [51]. Since the blood-retinal barrier is very similar to the blood-brain barrier, it is possible that EPO acts as an anti-permeability factor in the retina as well. In fact, EPO reduces diabetic macular oedema when administered systemically as a therapy to patients with an aemia and chronic renal failure [54].

Studies have also been conducted to evaluate the effect of EPO on pericytes. The initial results, which evaluated the utility of exogenous EPO as a vasoprotective and neuroprotective agent, are promising $[73,75]$. Pericytes play a fundamental role in maintaining the structural integrity of vessels and the blood-retinal barrier; they not only regulate the tone but also preserve the ability to produce prostacyclin, which protects against damage induced by lipid peroxidation. The loss and dysfunction of pericytes are among the earliest changes in the course of diabetic retinopathy, and determine many pathological changes [76]. The mechanism responsible for the loss of pericytes in the early DR is complex; high glucose levels, as well as AGEs, oxidative stress, and inflammation may cause apoptosis of retinal pericytes. Another mechanism is the NF- $\kappa B$ factor activation in retinal pericytes in response to hyperglycaemia. EPO could protect pericytes through its anti-oxidant and anti-inflammatory properties. Several mechanisms could be involved, for example, the reduction of the release of inflammatory cytokines, such as TNFa and IL1 $\beta$; the restoration of the integrity of cellular barriers interrupted by oxidative stress; the reduction of intracellular levels of reactive oxygen species the restoration of the antioxidant potential of cells; the total antioxidant capacity; glutathione peroxidase; superoxide dismutase; and the reduction of lipid peroxidation products [77].

EPO, beyond its anti-permeabilization, anti-inflammatory, and neuroprotective actions, protects from apoptosis induced by high glucose levels and the harmful effects of free radicals [51,78].

In addition, EPO is a potent physiological stimulus for the mobilization of endothelial progenitor cells (EPCs) [58] and, therefore, could play a significant role in regulating the movement of circulating EPCs to damaged retinal areas [44]. An early addition of systemic EPO prevents the loss of retinal blood vessels as well as the neovascularisation and pathological degeneration of retinal neurons [43]. During the vascular leakage phase of retinopathy, supplements of EPO can help prevent the loss of retinal vessels, and therefore, prevent pathological neovascularisation induced by hypoxia $[43,64]$. Chen et al. recently described a murine model of hypoxia-induced retinopathy and demonstrated that the administration of exogenous EPO during the initial phase prevents vascular leakage and apoptosis of retinal neurons induced by hypoxia; however, a late treatment with EPO may increase pathological neovascularisation [43]. The administration of exogenous EPO through intravitreal injections in rats with early diabetic retinopathy prevents the death of retinal cells and protects the functions of the blood-retinal barrier [73,75].

For all these reasons, the increased intraocular synthesis of EPO, which occurs in diabetic retinopathy, could repair the damage induced by diabetes.

However, in advanced stages when retinal hypoxia is predominant and when there are also high levels of VEGF, EPO contributes to neovascularization, and consequently, to the worsening of DR $[43,79]$. Moreover, in these later stages, the recruitment of EPCs could aggravate retinal neovascularisation [80]. Suppression of EPO during this phase might be beneficial and could be associated with the inhibition of VEGF [64].

During the proliferative phase of retinopathy, high levels of EPO in response to increased retinal hypoxia were mainly produced in the neuronal layer. The increased production of EPO-mRNA occurs especially in the inner and outer nuclear layers. The suppression by intravitreal injection of EPO-EPO siRNA (small interfering RNA, a new technology to suppress gene expression) could significantly suppress retinal neovascularisation [41].

Inhibition of EPO provides benefits in preventing neovascularization during the phase in which it occurs. The inhibition of EPO alone, however, does not completely inhibit neovascularization, indicating that other factors, such as VEGF, are active in promoting neovascularisation $[44,64]$.

It is not clear if EPO acts on cystoid macular oedema. However, it has been found repeatedly that EPO limits the extent of cerebral oedema in experimental models of brain damage [81,82]; EPO also improves macular oedema when administered for the treatment for anaemia in patients with diabetes and renal failure [54]. We can therefore hypothesize that EPO may have positive effects on the retina in cases of macular oedema.

Therefore, endogenous EPO may act in a dual role in the pathogenesis of diabetic retinopathy and may represent an interesting target to study in order to understand the physiological mechanisms and to evaluate new therapeutic strategies.

Further studies will be needed to understand whether ocular or systemic EPO may have a predictive role in diabetic retinopathy, as it has been shown to have for other systemic factors [83].

\section{EPO as a Future Therapy}

Since regulated oxygen/hypoxia growth factors play a role in stimulating retinal angiogenesis [84], the inhibition of these factors is a key approach in the inhibition of retinal neovascularisation [7].

To date, DR therapies have been mainly based on only one of these factors: VEGF. This hypoxia-regulated factor is essential for retinal neovascularization, and for this reason, a drug that inhibits its activity has long been used in intravitreal formulations. The inhibition of VEGF by intravitreal injection of bevacizumab (Avastin ${ }^{\circledR}$ ) or ranibizumab (Lucentis ${ }^{\circledR}$ ) is currently used successfully to suppress neovascularisation in macular degeneration and in diabetic retinopathy [85], but this therapy is not without complications [86]. 
However, not all patients are responsive to this therapy, and in some cases, the pathological condition persists, resulting in the loss of retinal neurons [87-89]. The prevention of neuronal death could represent a new target in the treatment of severe diabetic macular oedema [90].

The intravenous administration of EPO to treat anaemia in diabetic patients with renal impairment showed a beneficial effect in macularoedema and improvements in visual acuity [91]. In a 1961 study, it was shown that the severity of anaemia is related to these verities of DR [92]. Friedman reported 5 cases in which patients with severe anaemia and proliferative diabetic retinopathy showed a significant reduction in macular hard exudates after systemic treatment with EPO [93]. It is possible that the visual acuity improvement following therapy with EPO is mainly due to the neuroprotection mechanism, rather than resulting from an improvement in vascular leakage [88]. EPO has in fact been used in studies for the treatment of multiple sclerosis [94] and diabetic neuropathy [95].

Moreover, a restoration of function of Muller cells has been demonstrated through the action of EPO administered intraperitoneally to diabetic rats [96]. The neurotrophic and neuroprotective properties of EPO [73,94] as well as its cytoprotective and vascular-protective effects $[73,95]$ and its ability to protect the retinal pigment epithelium, are valid reasons for proposing EPO or agonists to EpoR as new therapeutic agents for the treatment of the early stages of diabetic retinopathy.

Some studies have evaluated the intravitreal effect of EPO in the eyes of patients with diabetic macular and severe chronic oedema [88]. These studies have shown a positive response in the short term, and patients benefiting from this treatment have shown increases in visual acuity. Recent studies have shown that a single intravitreal injection of $\mathrm{EPO}$ in the eyes of mice at the onset of diabetes mellitus prevents the death of retinal neurons and protects the integrity of the blood-retinal barrier [73]. In diabetic animals, intravitreal injection of EPO resulted in a reduction of vascular leakage [73].

A study has suggested that EPO may reduce the loss of pericytes in the early stages of DR, and therefore, could be used as a new therapeutic agent for the initial forms of DR based on its anti-oxidant, antiapoptotic, and neuroprotective properties [97]. Mitsuhashi et al. [98,99] reported that EPO may play an important role against the progression of diabetic retinopathy by reducing blood vessel degeneration in the very early stages of the disease [98].

EPO has a pharmacokinetic profile of rapid clearance that is optimal for intravitreal injections [99]. Intravitreal injection of EPO has been proven safe and is well-tolerated in rabbit eyes in a wide dose range. Lagrèze et al. [96] and Li et al. [91] reported that single or repeated intravitreal injections in humans are feasible and do not seem to cause any damage.

In order for EPO to become a viable option for the treatment of diabetic retinopathy, further studies in vivo and in vitro should be conducted and new technologies, such as the EMRA (ex vivo murine retina angiogenesis) technology we have studied and developed, should be used to better understand and develop potential applications of EPO in the treatment of eye diseases [100-102].

Future studies are needed to evaluate the risks and benefits of intravitreal EPO in humans and to define the specific pathways that regulate erythropoiesis, angiogenesis, and neuroprotection. However, the initial results support the hypothesis that EPO and its derivatives can reduce the loss of retinal pericytes and prevent or treat initial DR [97].

\section{References}

1. Ng T, Marx G, Littlewood T, Macdougall I (2003) Recombinant erythropoietin in clinical practice. Postgrad Med J 79: 367-376.

2. Hernández C, Simó R (2012) Erythropoietin produced by the retina: its role in physiology and diabetic retinopathy. Endocrine 41: 220-226.

3. Bartesaghi S, Marinovich M, Corsini E, Galli CL, Viviani B (2005) Erythropoietin a novel neuroprotective cytokine. Neurotoxicology 26: 923-928.

4. García-Ramírez M, Hernández C, Simó R (2008) Expression of erythropoietin and its receptor in the human retina: a comparative study of diabetic and nondiabetic subjects. Diabetes Care 31: 1189-1194.

5. Klein R, Klein BE, Moss SE, Davis MD, DeMets DL (1984) The Wisconsin epidemiologic study of diabetic retinopathy. II. Prevalence and risk of diabetic retinopathy when age at diagnosis is less than 30 years. Arch Ophthalmol 102 520-526.

6. Klein R, Klein BE, Moss SE, Davis MD, DeMets DL (1984) The Wisconsin epidemiologic study of diabetic retinopathy. III. Prevalence and risk of diabetic retinopathy when age at diagnosis is 30 or more years. Arch Ophthalmol 102 527-532.

7. dell'Omo R, Semeraro F, Bamonte G, Cifariello F, Romano MR, et al. (2013) Vitreous mediators in retinal hypoxic diseases. Mediators Inflamm 2013: 935301.

8. Erslev AJ (1991) Erythropoietin. N Engl J Med 324: 1339-1344.

9. Lin FK, Suggs S, Lin CH, Browne JK, Smalling R, et al. (1985) Cloning and expression of the human erythropoietin gene. Proc Natl Acad Sci U S A 82: 7580-7584.

10. Bazan JF (1990) Haemopoietic receptors and helical cytokines. Immunol Today 11: 350-354.

11. Jacobson Lo, Goldwasser E, Fried W, Plzak L (1957) Role of the kidney in erythropoiesis. Nature 179: 633-634.

12. Zanjani ED, Poster J, Burlington H, Mann LI, Wasserman LR (1977) Liver as the primary site of erythropoietin formation in the fetus. J Lab Clin Med 89: 640-644.

13. Hernández C, Fonollosa A, García-Ramírez M, Higuera M, Catalán R, et al (2006) Erythropoietin is expressed in the human retina and it is highly elevated in the vitreous fluid of patients with diabetic macular edema. Diabetes Care 29: 2028-2033.

14. Marti HH (2004) Erythropoietin and the hypoxic brain. J Exp Biol 207: 3233 3242.

15. Juul SE, Yachnis AT, Christensen RD (1998) Tissue distribution of erythropoietin and erythropoietin receptor in the developing human fetus. Early Hum Dev 52: 235-249.

16. Jelkmann W (2007) Erythropoietin after a century of research: younger than ever. Eur J Haematol 78: 183-205.

17. Semenza GL (2001) HIF-1, O(2), and the 3 PHDs: how animal cells signal hypoxia to the nucleus. Cell 107: 1-3.

18. Jelkmann W (2007) Control of erythropoietin gene expression and its use in medicine. Methods Enzymol 435: 179-197.

19. Jelkmann W (1998) Proinflammatory cytokines lowering erythropoietin production. J Interferon Cytokine Res 18: 555-559.

20. Morishita E, Masuda S, Nagao M, Yasuda Y, Sasaki R (1997) Erythropoietin receptor is expressed in rat hippocampal and cerebral cortical neurons, and erythropoietin prevents in vitro glutamate-induced neuronal death. Neuroscience 76: 105-116.

21. Digicaylioglu M, Bichet $\mathrm{S}$, Marti HH, Wenger RH, Rivas LA et al. (1995) Localization of specific erythropoietin binding sites in defined areas of the mouse brain. Proc Natl Acad Sci U S A 92: 3717-3720

22. Nagai A, Nakagawa E, Choi HB, Hatori K, Kobayashi S, et al. (2001) Erythropoietin and erythropoietin receptors in human CNS neurons, astrocytes, microglia, and oligodendrocytes grown in culture. J Neuropathol Exp Neurol 60: 386-392.

23. Farrell F, Lee A (2004) The erythropoietin receptor and its expression in tumor cells and other tissues. Oncologist 9 Suppl 5: 18-30. 
24. Kilic U, Kilic E, Soliz J, Bassetti CI, Gassmann M, et al. (2005) Erythropoietin protects from axotomy-induced degeneration of retinal ganglion cells by activating ERK-1/-2. FASEB J 19: 249-251.

25. Fisher JW (2003) Erythropoietin: physiology and pharmacology update. Exp Biol Med (Maywood) 228: 1-14.

26. Anagnostou A, Liu Z, Steiner M, Chin K, Lee ES, et al. (1994) Erythropoietin receptor mRNA expression in human endothelial cells. Proc Natl Acad Sci U S A 91: 3974-3978.

27. Peterson TE, Katusic ZS (2007) EPO tecting the endothelium. Br J Pharmacol 150: 823-825.

28. Jaquet K, Krause K, Tawakol-Khodai M, Geidel S, Kuck KH (2002) Erythropoietin and VEGF exhibit equal angiogenic potential. Microvasc Res 64: 326-333

29. Ribatti D, Presta M, Vacca A, Ria R, Giuliani R, et al. (1999) Human erythropoietin induces a pro-angiogenic phenotype in cultured endothelial cells and stimulates neovascularization in vivo. Blood 93: 2627-2636.

30. Chong ZZ, Kang JQ, Maiese K (2002) Erythropoietin is a novel vascular protectant through activation of Akt1 and mitochondrial modulation of cysteine proteases. Circulation 106: 2973-2979.

31. Digicaylioglu M, Lipton SA (2001) Erythropoietin-mediated neuroprotection involves cross-talk between Jak2 and NF-kappaB signalling cascades. Nature 412: 641-647.

32. Fisher JW (2010) Landmark advances in the development of erythropoietin Exp Biol Med (Maywood) 235: 1398-1411.

33. Jelkmann W (2005) Effects of erythropoietin on brain function. Curr Pharm Biotechnol 6: 65-79.

34. Li Y, Lu Z, Keogh CL, Yu SP, Wei L (2007) Erythropoietin-induced neurovascular protection, angiogenesis, and cerebral blood flow restoration after focal ischemia in mice. J Cereb Blood Flow Metab 27: 1043-1054.

35. Brines ML, Ghezzi P, Keenan S, Agnello D, de Lanerolle NC, et al. (2000) Erythropoietin crosses the blood-brain barrier to protect against experimental brain injury. Proc Natl Acad Sci U S A 97: 10526-10531.

36. Celik M, Gökmen N, Erbayraktar S, Akhisaroglu M, Konakc S, et al. (2002) Erythropoietin prevents motor neuron apoptosis and neurologic disability in experimental spinal cord ischemic injury. Proc Natl Acad Sci U S A 99: 22582263.

37. Calapai G, Marciano MC, Corica F, Allegra A, Parisi A, et al. (2000) Erythropoietin protects against brain ischemic injury by inhibition of nitric oxide formation. Eur J Pharmacol 401: 349-356.

38. Genc S, Kuralay F, Genc K, Akhisaroglu M, Fadiloglu S, et al. (2001) Erythropoietin exerts neuroprotection in 1-methyl-4-phenyl-1,2,3,6tetrahydropyridine-treated C57/BL mice via increasing nitric oxide production. Neurosci Lett 298: 139-141.

39. Sakanaka M, Wen TC, Matsuda S, Masuda S, Morishita E, et al. (1998) In vivo evidence that erythropoietin protects neurons from ischemic damage. Proc Natl Acad Sci U S A 95: 4635-4640.

40. Junk AK, Mammis A, Savitz SI, Singh M, Roth S, et al. (2002) Erythropoietin administration protects retinal neurons from acute ischemia-reperfusion injury. Proc Natl Acad Sci U S A 99: 10659-10664.

41. Chen J, Connor KM, Aderman CM, Willett KL, Aspegren OP, et al. (2009) Suppression of retinal neovascularization by erythropoietin siRNA in a mouse model of proliferative retinopathy. Invest Ophthalmol Vis Sci 50: 1329-1335.

42. Kase S, Saito W, Ohgami K, Yoshida K, Furudate N, et al. (2007) Expression of erythropoietin receptor in human epiretinal membrane of proliferative diabetic retinopathy. $\mathrm{Br} \mathrm{J}$ Ophthalmol 91: 1376-1378

43. Chen J, Connor KM, Aderman CM, Smith LE (2008) Erythropoietin deficiency decreases vascular stability in mice. J Clin Invest 118: 526-533.

44. Grimm C, Wenzel A, Groszer M, Mayser H, Seeliger M, et al. (2002) HIF-1induced erythropoietin in the hypoxic retina protects against light-induced retinal degeneration. Nat Med 8: 718-724.

45. Shah SS, Tsang SH, Mahajan VB (2009) Erythropoetin receptor expression in the human diabetic retina. BMC Res Notes 2: 234

46. Becerra SP, Amaral J (2002) Erythropoietin--an endogenous retinal survival factor. N Engl J Med 347: 1968-1970.
47. Rex TS, Wong Y, Kodali K, Merry S (2009) Neuroprotection of photoreceptors by direct delivery of erythropoietin to the retina of the retinal degeneration slow mouse. Exp Eye Res 89: 735-740.

48. Shen J, Wu Y, Xu JY, Zhang J, Sinclair SH, et al. (2010) ERK- and Aktdependent neuroprotection by erythropoietin (EPO) against glyoxal-AGEs via modulation of Bcl-xL, Bax, and BAD. Invest Ophthalmol Vis Sci 51: 35-46.

49. Böcker-Meffert S, Rosenstiel P, Röhl C, Warneke N, Held-Feindt J, et al. (2002) Erythropoietin and VEGF promote neural outgrowth from retinal explants in postnatal rats. Invest Ophthalmol Vis Sci 43: 2021-2026.

50. Chong ZZ, Kang JQ, Maiese K (2003) Erythropoietin: cytoprotection in vascular and neuronal cells. Curr Drug Targets Cardiovasc Haematol Disord 3: 141-154.

51. Liu J, Narasimhan P, Song YS, Nishi T, Yu F, et al. (2006) Epo protects SOD2deficient mouse astrocytes from damage by oxidative stress. Glia 53: 360-365.

52. Tsai JC, Wu L, Worgul B, Forbes M, Cao J (2005) Intravitreal administration of erythropoietin and preservation of retinal ganglion cells in an experimental rat model of glaucoma. Curr Eye Res 30: 1025-1031.

53. Martínez-Estrada OM, Rodríguez-Millán E, González-De Vicente E, Reina M Vilaró S, et al. (2003) Erythropoietin protects the in vitro blood-brain barrier against VEGF-induced permeability. Eur J Neurosci 18: 2538-2544.

54. Berman DH, Friedman EA (1994) Partial absorption of hard exudates in patients with diabetic end-stage renal disease and severe anemia after treatment with erythropoietin. Retina 14: 1-5

55. Friedman EA, L'Esperance FA, Brown CD, Berman DH (2003) Treating azotemia-induced anemia with erythropoietin improves diabetic eye disease. Kidney Int Suppl : S57-63.

56. Villa P, Bigini P, Mennini T, Agnello D, Laragione T, et al. (2003) Erythropoietin selectively attenuates cytokine production and inflammation in cerebral ischemia by targeting neuronal apoptosis. J Exp Med 198: 971-975.

57. Chung H, Lee H, Lamoke F, Hrushesky WJ, Wood PA, et al. (2009) Neuroprotective role of erythropoietin by antiapoptosis in the retina. J Neurosci Res 87: 2365-2374.

58. Garcia-Ramírez M, Hernández C, Ruiz-Meana M, Villarroel M, Corraliza L, et al. (2011) Erythropoietin protects retinal pigment epithelial cells against the increase of permeability induced by diabetic conditions: essential role of JAK2/ PI3K signaling. Cell Signal 23:1596-1602.

59. Heeschen C, Aicher A, Lehmann R, Fichtlscherer S, Vasa M, et al. (2003) Erythropoietin is a potent physiologic stimulus for endothelial progenitor cell mobilization. Blood 102: 1340-1346.

60. Ciulla TA, Amador AG, Zinman B (2003) Diabetic retinopathy and diabetic macular edema: pathophysiology, screening, and novel therapies. Diabetes Care 26: 2653-2664.

61. Sander B, Larsen M, Moldow B, Lund-Andersen H (2001) Diabetic macular edema: passive and active transport of fluorescein through the blood-retina barrier. Invest Ophthalmol Vis Sci 42: 433-438.

62. Aiello LP, Bursell SE, Clermont A, Duh E, Ishii H, et al. (1997) Vascular endothelial growth factor-induced retinal permeability is mediated by protein kinase $C$ in vivo and suppressed by an orally effective beta-isoform-selective inhibitor. Diabetes 46: 1473-1480.

63. Sfikakis PP, Markomichelakis N, Theodossiadis GP, Grigoropoulos V Katsilambros N, et al. (2005) Regression of sight-threatening macular edema in type 2 diabetes following treatment with the anti-tumor necrosis factor monoclonal antibody infliximab. Diabetes Care28: 445-447.

64. Aiello LP (2005) Angiogenic pathways in diabetic retinopathy. N Engl J Med 353: 839-841.

65. Watanabe D, Suzuma K, Matsui S, Kurimoto M, Kiryu J, et al. (2005) Erythropoietin as a retinal angiogenic factor in proliferative diabetic retinopathy N Engl J Med 353: 782-792.

66. Asensio-Sánchez VM, Gómez-Ramírez V, Morales-Gómez I (2008) [Erythropoietin concentrations in the vitreous body from patients with proliferative diabetic retinopathy]. Arch Soc Esp Oftalmol 83: 169-172.

67. Inomata Y, Hirata A, Takahashi E, Kawaji T, Fukushima M, et al. (2004) Elevated erythropoietin in vitreous with ischemic retinal diseases. Neuroreport 15: 877-879.

68. Stahl A, Buchwald A, Martin G, Junker B, Chen J, et al. (2010) Vitreal levels of erythropoietin are increased in patients with retinal vein occlusion and correlate with vitreal VEGF and the extent of macular edema. Retina 30: 1524-1529. 
69. Joussen AM, Poulaki V, Le ML, Koizumi K, Esser C, et al. (2004) A central role for inflammation in the pathogenesis of diabetic retinopathy. FASEB $\mathrm{J} 18$ : 1450-1452.

70. Kim JY, Kim YG, Baik JY, Joo EJ, Kim YH, et al. (2010) A proteomic approach for identifying cellular proteins interacting with erythropoietin in recombinan Chinese hamster ovary cells. Biotechnol Prog 26: 246-251.

71. Darling RJ, Kuchibhotla U, Glaesner W, Micanovic R, Witcher DR, et al (2002) Glycosylation of erythropoietin affects receptor binding kinetics: role of electrostatic interactions. Biochemistry 41: 14524-14531.

72. Gross AW, Lodish HF (2006) Cellular trafficking and degradation of erythropoietin and novel erythropoiesis stimulating protein (NESP). J Biol Chem 281: 2024-2032

73. Layton CJ, Wood JP, Chidlow G, Osborne NN (2005) Neuronal death in primary retinal cultures is related to nitric oxide production, and is inhibited by erythropoietin in a glucose-sensitive manner. J Neurochem 92: 487-493.

74. Zhang J, Wu Y, Jin Y, Ji F, Sinclair SH, et al. (2008) Intravitreal injection of erythropoietin protects both retinal vascular and neuronal cells in early diabetes. Invest Ophthalmol Vis Sci 49: 732-742.

75. Wang Q, Gorbey S, Pfister F, Höger S, Dorn-Beineke A, et al. (2011) Longterm treatment with suberythropoietic Epo is vaso- and neuroprotective in experimental diabetic retinopathy. Cell Physiol Biochem 27: 769-782.

76. Zhang J, Hu LM, Xu G, Wu Y, Shen J, et al. (2010) Anti-VEGF effects of intravitreal erythropoietin in early diabetic retinopathy. Front Biosci (Elite Ed) 2: 912-927.

77. Ejaz S, Chekarova I, Ejaz A, Sohail A, Lim CW (2008) Importance of pericytes and mechanisms of pericyte loss during diabetes retinopathy. Diabetes Obes Metab 10: 53-63.

78. Wang ZY, Shen LJ, Tu L, Hu DN, Liu GY, et al. (2009) Erythropoietin protects retinal pigment epithelial cells from oxidative damage. Free Radic Biol Med 46: 1032-1041.

79. Sekiguchi N, Inoguchi T, Kobayashi K, Sonoda N, Nawata H (2005) Erythropoietin attenuated high glucose-induced apoptosis in cultured human aortic endothelial cells. Biochem Biophys Res Commun 334: 218-222.

80. Grant MB, Boulton ME, Ljubimov AV (2008) Erythropoietin: when liability becomes asset in neurovascular repair. J Clin Invest 118: 467-470.

81. Hu LM, Lei X, Ma B, Zhang Y, Yan Y, et al. (2011) Erythropoietin receptor positive circulating progenitor cells and endothelial progenitor cells in patients with different stages of diabetic retinopathy. Chin Med Sci 26: 69-76.

82. Grasso G, Sfacteria A, Meli F, Fodale V, Buemi M, et al. (2007) Neuroprotection by erythropoietin administration after experimental traumatic brain injury. Brain Res 1182: 99-105.

83. Shein NA, Grigoriadis N, Alexandrovich AG, Simeonidou C, Spandou E, et al (2008) Differential neuroprotective properties of endogenous and exogenous erythropoietin in a mouse model of traumatic brain injury. J Neurotrauma 25 112-123.

84. Semeraro F, Parrinello G, Cancarini A, Pasquini L, Zarra E, et al. (2011) Predicting the risk of diabetic retinopathy in type 2 diabetic patients. J Diabetes Complications 25: 292-297.

85. Gariano RF, Gardner TW (2005) Retinal angiogenesis in development and disease. Nature 438: 960-966.

86. Costagliola C, Daniele A, dell'Omo R, Romano MR, Aceto F, et al. (2013) Aqueous humor levels of vascular endothelial growth factor and adiponectin in patients with type 2 diabetes before and after intravitreal bevacizumab injection. Exp Eye Res 110: 50-54
87. Semeraro F, Morescalchi F, Parmeggiani F, Arcidiacono B, Costagliola C (2011) Systemic adverse drug reactions secondary to anti-VEGF intravitrea injection in patients with neovascular age-related macular degeneration. Cur Vasc Pharmacol 9: 629-646.

88. (1985) Early vitrectomy for severe vitreous hemorrhage in diabetic retinopathy. Two-year results of a randomized trial. Diabetic Retinopathy Vitrectomy Study report 2. The Diabetic Retinopathy Vitrectomy Study Research Group. Arch Ophthalmol 103:1644-1652.

89. Ahmadieh H, Ramezani A, Shoeibi N, Bijanzadeh B, Tabatabaei A, et al. (2008) Intravitreal bevacizumab with or without triamcinolone for refractory diabetic macular edema; a placebo-controlled, randomized clinical trial. Graefes Arch Clin Exp Ophthalmol 246: 483-489.

90. Fletcher EL, Phipps JA, Ward MM, Puthussery T, Wilkinson-Berka JL (2007) Neuronal and glial cell abnormality as predictors of progression of diabetic retinopathy. Curr Pharm Des 13: 2699-2712.

91. Li W, Sinclair SH, Xu GT (2010) Effects of intravitreal erythropoietin therapy for patients with chronic and progressive diabetic macular edema. Ophthalmic Surg Lasers Imaging 41: 18-25.

92. Semenza GL (1994) Regulation of erythropoietin production. New insights into molecular mechanisms of oxygen homeostasis. Hematol Oncol Clin North Am 8: 863-884.

93. Qiao Q, Keinänen-Kiukaanniemi S, Läärä E (1997) The relationship between hemoglobin levels and diabetic retinopathy. J Clin Epidemiol 50: 153-158.

94. Friedman EA, Brown CD, Berman DH (1995) Erythropoietin in diabetic macular edema and renal insufficiency. Am J Kidney Dis 26: 202-208.

95. Ehrenreich H, Fischer B, Norra C, Schellenberger F, Stender N, et al. (2007) Exploring recombinant human erythropoietin in chronic progressive multiple sclerosis. Brain 130: 2577-2588.

96. Lagrèze WA, Feltgen N, Bach M, Jehle $T$ (2009) Feasibility of intravitreal erythropoietin injections in humans. Br J Ophthalmol 93: 1667-1671.

97. Zhu B, Wang W, Gu Q, Xu X (2008) Erythropoietin protects retinal neuron and glial cells in early-stage streptozotocin-induced diabetic rats. Exp Eye Res 86: 375-382.

98. Wang ZY, Zhao KK, Zhao PQ (2011) Erythropoietin therapy for early diabetic retinopathy through its protective effects on retinal pericytes. Med Hypotheses 76: 266-268.

99. Mitsuhashi J, Morikawa S, Shimizu K, Ezaki T, Yasuda Y, et al. (2013) Intravitrea injection of erythropoietin protects against retinal vascular regression at the early stage of diabetic retinopathy in streptozotocin-induced diabetic rats. Exp Eye Res 106: 64-73.

100.Zhang JF, Wu YL, Xu JY, Ye W, Zhang Y, et al. (2008) Pharmacokinetic and toxicity study of intravitreal erythropoietin in rabbits. Acta Pharmacol Sin 29 1383-1390.

101. Rezzola S, Belleri M, Ribatti D, Costagliola C, Presta M, et al. (2013) A nove ex vivo murine retina angiogenesis (EMRA) assay. Exp Eye Res 112: 51-56.

102. Angi M, Kalirai H, Coupland SE, Damato BE, Semeraro F, et al. (2012) Proteomic analyses of the vitreous humour. Mediators Inflamm 2012: 148039.
This article was originally published in a special issue, Type 2 Diabetes Mellitus- Disease, Diagnosis \& Treatment handled by Editors. Dr. Judit Bene, University of Pécs, Hungary; Eun Seok Kang, Yonsei University College of Medicine, Korea
Volume $4 \cdot$ Issue $6 \cdot 1000283$ 